\title{
Artificial lightning strike tests and coupled electrical-thermal analysis on roofing glazed tiles of ancient buildings
}

\author{
Jingxiao Li ${ }^{1}$, Zhiling Fang ${ }^{1}$, Lin Fu', Shangchen $\mathrm{Fu}^{2 *}$, Lihua Shi ${ }^{2}$, Yun $\mathrm{Li}^{2}$ and Peidong Huo
}

\begin{abstract}
Lightning strike is one of the natural disasters to the roof components of ancient buildings. To investigate the causes and damage effects of lightning strikes on the roofing glazed tiles of ancient buildings, artificial lightning strike tests were carried out on glazed tiles. Based on the experiment results, a coupled electrical-thermal finite element model of mortar-containing glazed tiles was established and the Joule heat effect of lightning current was further investigated. The results show that when the lightning channel is attached to the surface of the enamel and body with a low electrical conductivity, the lightning current is mainly released in the form of surface flashover, and a minor damage is induced along the flashover path; when the lightning channel is attached to the mortar with a high electrical conductivity, the lightning current is injected into the mortar, resulting in significant tile damage. The spatial distributions of the temperature present clear gradient characteristics. The high-temperature area appears in the mortar while the high-thermal-stress area appears in the body connected to the grounding rail. As the peak of the lightning current increases, both the high-temperature and high-thermal-stress areas of the glazed tiles expand. The combination of the experiments and the numerical analysis results demonstrate that the damage mechanism of lightning Joule heat effect to glazed tiles may include two aspects. One is the internal explosive force generated from the sharp vaporization and expansion of the moisture inside the tiles due to rapid temperature increase, and the other is the thermal stress caused by the uneven temperature distribution.
\end{abstract}

Keywords: Glazed tiles, Lightning damage testing, Coupled electrical-thermal effect, Temperature, Thermal stress

\section{Introduction}

As a precious cultural heritage, ancient architecture has great scientific, artistic, and tourist value. Glazed tiles, which are key roof components of ancient buildings, present distinct characteristics of the period in which they were laid. They vividly and intuitively reflect the cultural and technical prowess of bygone times and play an important role in studying ancient architecture $[1,2]$. Glazed tiles are non-renewable, and any man-made or natural damage is irreparable. Because of their position,

\footnotetext{
*Correspondence: fshangchen@hotmail.com

${ }^{2}$ National Key Laboratory on Electromagnetic Environmental Effects and Electro-Optical Engineering, Army Engineering University of PLA, Nanjing 210007, China

Full list of author information is available at the end of the article
}

material, and structure, ancient buildings are vulnerable to lightning strike damage. Glazed tiles are typically laid on top of ancient buildings and are particularly exposed to lightning strikes. Under the effect of lightning current, glazed tiles are subjected to various types of damages, including fractures, breakage, and collapse; it can even lead to the burning of the entire building, resulting in incalculable losses. Among the factors that cause glazed tile damage in ancient buildings, the lightning damage is one of the main natural disasters $[3,4]$.

Although the lightning strike problems of buildings have been discovered for a long time in ancient time, e.g.in China [5], in Egypt [6], the protection measures were able to be implemented only after mid-eighteenth century based on the outcome of Benjamin Franklin [7]

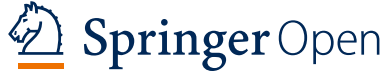

(c) The Author(s) 2021. Open Access This article is licensed under a Creative Commons Attribution 4.0 International License, which permits use, sharing, adaptation, distribution and reproduction in any medium or format, as long as you give appropriate credit to the original author(s) and the source, provide a link to the Creative Commons licence, and indicate if changes were made. The images or other third party material in this article are included in the article's Creative Commons licence, unless indicated otherwise in a credit line to the material. If material is not included in the article's Creative Commons licence and your intended use is not permitted by statutory regulation or exceeds the permitted use, you will need to obtain permission directly from the copyright holder. To view a copy of this licence, visit http://creativecommons.org/licenses/by/4.0/. The Creative Commons Public Domain Dedication waiver (http://creativeco mmons.org/publicdomain/zero/1.0/) applies to the data made available in this article, unless otherwise stated in a credit line to the data. 
and V. P. Diviš [8].The lightning protection systems have been installed in many ancient buildings. However, there is a certain probability of interception failure for protection systems, so some lightning strike incidents are still found on the roof components of ancient buildings installed with lightning protection systems [5]. Therefore, it is very necessary to study the causes and damage effects of lightning strikes on the roofing glazed tiles.

Researchers have carried out related studies on the mechanism of lightning strike through building components. Huang et al. [9] conducted lightning experiments on building material samples and model blocks from the Palace Museum. They found that the combined impulse voltage of tiles, mortar, and wooden plate was lower than the sum of the individual impulse strengths of the three materials. Chen et al. [10] performed simulations of lightning ablation or cracking experiments on the golden roof of Potala Palace, Baima White Wall, and Alga soil using an impulse current generator, demonstrating that the grass wall can easily ignite under long or multiple lightning strikes. Li et al. [11] experimentally investigated the factors affecting the lightning damages of the timber components of ancient buildings, including the lightning current, timber moisture content, and timber density. In addition, investigations on the lightning damage of reinforced concrete structures have been reported [12-14]. Chen et al. [15] found that the electrical-thermal coupling effect induces vaporization and rapid expansion of the water inside the concrete components of the building, causing damage. These studies provided some reference for analyzing lightning damage effects in glazed tiles. However, the results can hardly be directly applied to glazed tiles owing to their unique characteristics and material. In addition, the experimental studies on lightning damage to glazed tiles are lacking, and investigations on the causes of damage are also insufficient.

From the perspective of lightning protection, researchers have been conducting more studies related to the lightning damage mechanism of aircraft composite structures in recent years. The methodology they developed, implementing equivalent lightning strike tests under laboratory conditions to investigate the damage causes[16, 17], and then combining with numerical simulations to further analyze the damage effects $[18,19]$, provide effective reference methods for studying the lightning damage mechanism of glazed tiles and the corresponding damage effects.

\section{Research aims}

In this paper, lightning damage causes and damage effect of ancient roofing glazed tiles were investigated with artificial lightning current tests and numerical analysis. First, tests were conducted on the glazed tiles of ancient buildings containing enamel, body, and mortar using a lightning current generator, where a high-speed camera was used to monitor the conduction process of the currents under different lightning strike positions. The causes of lightning damage were then discussed. Based on the experiment results, coupled electrical-thermal finite element analysis on mortar-containing glazed tiles were carried out to further study the influence of lightning Joule heat effect. The relationship between the temperature field and time was analyzed, and the distributions of the temperature and thermal stress under different lightning current peak were compared. In addition, the damage rule of Joule heat produced by the lightning current on the glazed tiles was obtained. The combination of the experiment and the numerical analysis results demonstrated the damage mechanism and process of lightning Joule heat effect to glazed tiles.

\section{Materials and methods \\ Materials}

The specimens used in this study were provided by Beijing Research Institute of Architectural Heritages (Fig. 1a). The glazed tiles comprise round and plate tiles with the same material but different shapes and structures. The round tile is covered at the connection point of the two ridges of the plate tiles and has a raised arc shape and semicircular section, whereas the plate tile is above the round tile and is likely to be struck by lightning. The glazed round tiles (hereinafter referred to as glazed tiles) were selected in this study. Glazed tiles were fired using aluminum silicates with enamel applied to the surface. The specimens had a width of $1.8 \mathrm{~cm}$, a full-block length of $35 \mathrm{~cm}$, an outer cross-sectional diameter of $14.4 \mathrm{~cm}$, and a height of $7.2 \mathrm{~cm}$.

The glazed tile is made of body, enamel, and mortar (Fig. 1b). The body is the main part of the glazed tile. The major components of the body are $\mathrm{SiO}_{2}$ and $\mathrm{Al}_{2} \mathrm{O}_{3}$, accounting for $37-68 \%$ and $11-36 \%$ of the total amount, respectively, and there are few other compounds such as $\mathrm{Fe}_{2} \mathrm{O}_{3}, \mathrm{CaO}$, and $\mathrm{MgO}$. The enamel in the form of lead silicate glass and with an average thickness of $130 \mu \mathrm{m}$ was applied to the body surface for playing decoration and resisting water. To ensure a strong connection and waterproofing between the adjacent tiles, a tongue-like tenon (it is called "bear head" in the field of ancient architecture) was fired at the top of each glazed tile piece. A grayish-white substance coated on the surface for bonding is called the mortar, which is composed of $\mathrm{CaCO}_{3}$, $\mathrm{Mg}(\mathrm{OH})_{2}, \mathrm{SiO}_{2}$, and $\mathrm{NaAlSi}_{3} \mathrm{O}_{8}$.

Among the three components of a glazed tile, the body has similar conductivity as that of enamel, which is very low. The four-electrode method is used to evaluate the body conductivity, which is found to be approximately 

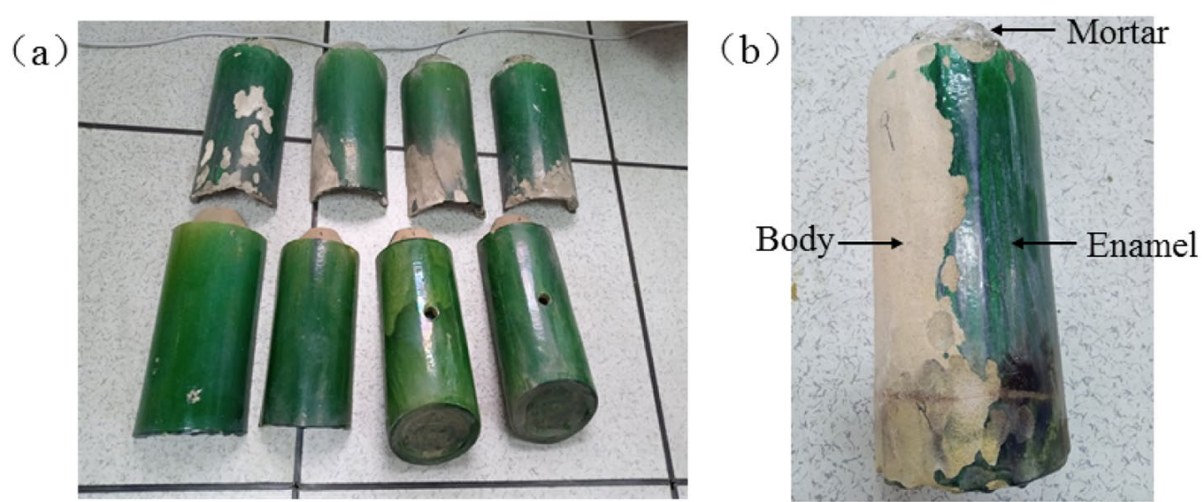

Fig. 1 Specimens of a relatively intact glazed tiles; $\mathbf{b}$ half enamel and half body tile

$8 \times 10^{-8} \mathrm{~S} / \mathrm{m}$. Compared with the body and enamel, the mortar exhibits much higher conductivity. As the conductivity of the mortar is typically in the range of 0.55 $0.63 \mathrm{~S} / \mathrm{m}$ [20], we set the mortar conductivity as $0.6 \mathrm{~S} / \mathrm{m}$ (moisture content $=25 \%$ ) in this study.

According to the components of glazed tiles, there are four possible attachment locations when encountered with lightning strike. Hence, the specimens were divided into four groups, and each contained two specimens, as shown Table 1. The first group is full enamel specimens, which is used to simulate the situation of lightning current attached to complete glazed tiles. The second and the third group simulate the situation of attachment to different position of glazed tiles with exposed bodies, respectively. The last group simulates the attachment to mortar area. Additionally, besides the components, the moisture content of the tiles may also influence the lightning damage effect, and this has been investigated in another paper [21].

\section{Lightning strike test method}

The artificial lightning current in the experiments is generated using an impulse current generator (ICTS $10 / 350 \& 8 / 20-200 / 200$, produced by Xi'an Jiaotong
University, China), referring to the lightning damage experiments conducted in previous studies [16, 17]. The lightning current was generated using a customized impulse current generator shown in Fig. 2a, and the waveform it generated was $8 / 20 \mu$ s (rise time/halfpeak time). Due to the condition of the equipment, the impulse current waveform applied in this experiment is $8 / 20 \mu$ s (rise time/half-peak time). Although the parameters are different from the $10 / 350 \mu$ s waveform provided in IEC 62305.1-2010, their peak current amplitude, action integral and time duration, which are of primary importance for direct effects evaluations, are all on the same level. In addition, the setup is identical with the real lightning strike process, so the $8 / 20 \mu$ s lightning current waveform was used during the experiments.

The lightning current was conducted by the diversion strip, and then injected into the specimens through a copper probe fixed above the glazed tiles. The distance between the copper probe tip and the specimens was set to $2 \mathrm{~mm}$ to ensure the arc discharge. The specimens were clamped with a custom fixture, and grounded by two copper guide rails fixed on two sides, as shown in Fig. $2 \mathrm{~b}$.

The peak value of the impulse current is selected as 40 $\mathrm{kA}$ and Fig. 1c shows the waveform of the current collected

Table 1 Glazed tile specimens of four groups

\begin{tabular}{llll}
\hline No & Specimen type & $\begin{array}{l}\text { Attachment location of } \\
\text { lightning channel }\end{array}$ & $\begin{array}{l}\text { No. of } \\
\text { specimens }\end{array}$ \\
\hline 1 & Full-enamel specimens & Central arc point of enamel & $1 \#$ \\
2 & Full-body specimens & Central arc point of body & $3 \#$ \\
3 & Semi-enamel, semi-body specimens & Central point of the junction of enamel and body $\quad 5 \#$ & $6 \#$ \\
4 & Mortar-containing specimens & Central point of mortar & $7 \#$ \\
\hline
\end{tabular}




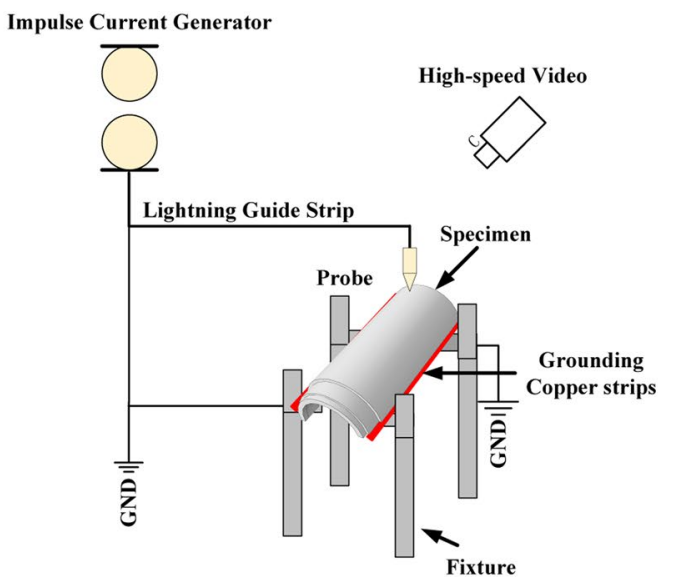

(a)

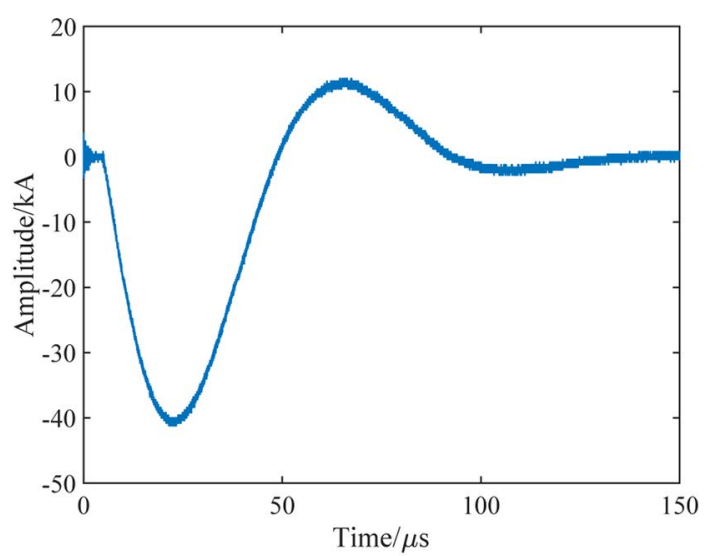

(c)

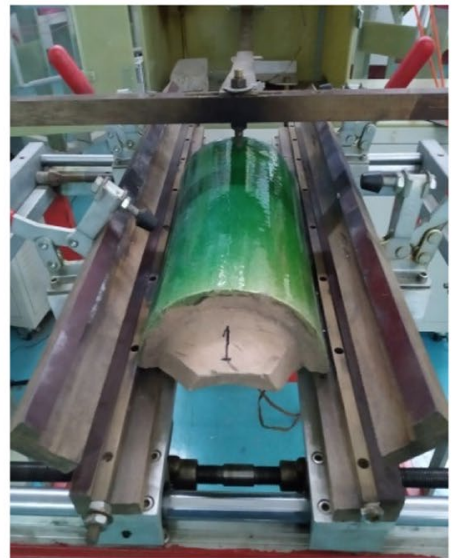

(b)

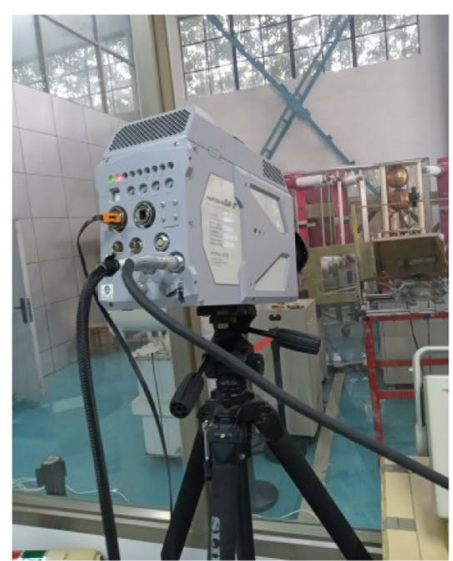

(d)

Fig. 2 Experimental setup for artificial lightning strike Test, a Schematic of experimental setup; $\mathbf{b}$ Image of experimental setup; $\mathbf{c}$ Waveform of the impulse current in the experiments; $\mathbf{d}$ High-speed camera

using an oscilloscope (MDO 3024, Tektronix Co., America) during the experiments. A high-speed camera (FASTCAM SA-Z, Photron, Japan) (Fig. 1d) was used in the experiments to monitor the formation, development of the arc channel at the probe tip, and its interaction with the specimens. The frame rate of the high-speed camera was set to 700,000 frame/s.

\section{Coupled electrical-thermal analysis method Basic theory of coupled electrical-thermal analysis}

When the lightning current attaches to the mortar surface and enters inside, the charge conservation equation should be satisfied during the conduction. The generated electricity can be represented as $[18,22]$ :

$$
P_{e c}=E \cdot J=E \cdot \sigma^{E} \cdot E
$$

where $J$ is the current density, $E$ is the electric field strength, and $\sigma^{E}$ is the conductivity matrix of the mortar, which is written as:

$$
\sigma^{E}=\sigma^{E}\left(\theta, f^{\alpha}\right)
$$

where $\theta$ denotes the temperature, and $f^{\alpha},(\alpha=1,2, \ldots)$ denotes the structure-dependent predefined field quantities that are related to the mortar structure.

The above two formulae show that the temperature change will lead to a change in the electrical conductivity of the mortar structure and then affect the magnitude of the electric energy generated when the lightning current propagates in the mortar. Under the action of Joule heat, a part of the electrical energy generated by the lightning current is converted into heat energy:

$$
r=\eta_{v} P_{e c}
$$


where $\eta_{v}$ is the energy conversion factor. The heat energy after conversion follows the basic heat equilibrium equation in the mortar structure for propagation:

$$
\begin{aligned}
& \int_{V} \rho C_{V} \frac{\partial \theta}{\partial t} \delta \theta d V+\int_{V} \nabla \delta \theta \cdot K \cdot \nabla \theta d V \\
& =\int_{V} \delta \theta r d V+\int_{S} \delta \theta q d S
\end{aligned}
$$

where $\rho, C_{V}$, and $K$ are the density, specific heat, and thermal conductivity matrices of the mortar material, respectively, and $q$ is the heat flux per unit region inside the material. According to Eq. (4), the heat generated by Joule heat will lead to a change in the temperature of the mortar material.

For the destruction of thermal stress, if the temperature rise of two adjacent elements is $\Delta \mathrm{T} 1$ and $\Delta \mathrm{T} 2$, then the thermal stress $f$ generated under the action of temperature gradient is

$$
f=\frac{E a}{1-\mu}\left(\Delta T_{1}-\Delta T_{2}\right)
$$

where $E$ is the elastic modulus; a denotes the coefficient of thermal expansion; and $\mu$ is Poisson's ratio.

In summary, since the mortar conductivity $\sigma^{E}$ is a function of the temperature, the electrical conductivity will vary with the temperature. Joule heat generated due to the propagation of lightning current in the mortar material is the result of electrical energy conversion, i.e., the thermal energy generated in the tiles will be affected by the propagating current. The existence of the mortar material makes the conduction process of heat and electricity interrelated, leading to a coupled electrical-thermal effect. As the lightning current continues to pass through the mortar material, the temperature of the material increases due to Joule heat and is conducted to the adjacent body part. The combination of explosive force and thermal stress induces the damage of the tiles.

\section{Damage threshold analysis}

Because of the voids inside the glazed tile, the body and mortar have porosities approximately in the ranges of $10-30 \%$ [23] and $16-50 \%$, respectively [20]. This ensures that the tiles will store some moisture during the thunderstorm season. The moisture content in the tile body is approximately in the range of $15-20 \%$ [24], and in the mortar is approximately in the range of 9-42\% [20]. When encountered with lightning current, the moisture in these voids vaporizes and expands rapidly because of Joule heat effects. However, the pores inside the glazed tile act nearly as confined spaces, and the adiabatic environment during transient lightning strike will block the heat exchange, which makes it very difficult for the water vapor to release, and eventually, an internal burst will be induced. The pressure from the vaporization of the water per unit mass in the pores of the glazed tiles can be calculated using the Clapeyron equation:

$$
P=\frac{\rho R T}{M}
$$

where $M$ is the molar mass of water, $18 \mathrm{~g} / \mathrm{mol} ; \rho$ is the density of water, $1000 \mathrm{~kg} / \mathrm{m}^{3} ; R$ is the gas constant, $8.314 \mathrm{~J} / \mathrm{mol} / \mathrm{K} ; T$ is the thermodynamic temperature, which is $373.15 \mathrm{~K}$ for vapor.

Therefore, it can be calculated that the pressure is approximately $0.172 \mathrm{GPa}$ after the water instantly changes into water vapor in the voids of the glazed tiles. Because the internal pores are approximately closed spaces with a limited volume, the pressure increases, and an explosive force is produced because of the sharp expansion of the water in the tiles. According to Clapeyron Eq. (6), the boiling point of the water will be increase with if the pressure increases. However, the temperature first reaches the boiling point, then the water inside pore becomes vapor, and then the pressure inside closed pore increases. Furthermore, because of the significant energy of lightning current, the boiling of the water, as well as its vaporization and the increase of the pressure almost occur simultaneously in about several microseconds, so the increase of boiling point after the pressure increase is not considered temporarily.

Besides the explosion force, another consequence caused by Joule heat effect is rapid temperature variation, resulting in local regional heterogeneous temperature distribution and significant thermal stress. Since glazed tiles are solid-state structure, which are unlikely to deform, and the tiles cannot offset the effects of the explosive force and thermal stress by stretching themselves, the cracks or even fracture damage can easily occur [25]. Therefore, the value of $0.172 \mathrm{GPa}$ can be considered as the initial threshold for the initiation of damage. In addition, according to reference [26], cracking will occur when the stress of the tile exceeds approximately $0.9 \mathrm{GPa}$. After blast, the conduction of lightning current will be suspended, and Joule heat effect will disappear, so the influence of explosion force and thermal stress will terminate. Therefore, the upper threshold can be considered to be $0.9 \mathrm{GPa}$.

\section{Numerical modeling process}

The coupled electrical-thermal analysis is carried out with commercial finite element software ABAQUS 6.14. The dimension and the electric boundary condition of the model are both the same as the experimental setup, and the center of the mortar area is selected as the lightning attachment point, as shown in Fig. 3. For thermal 


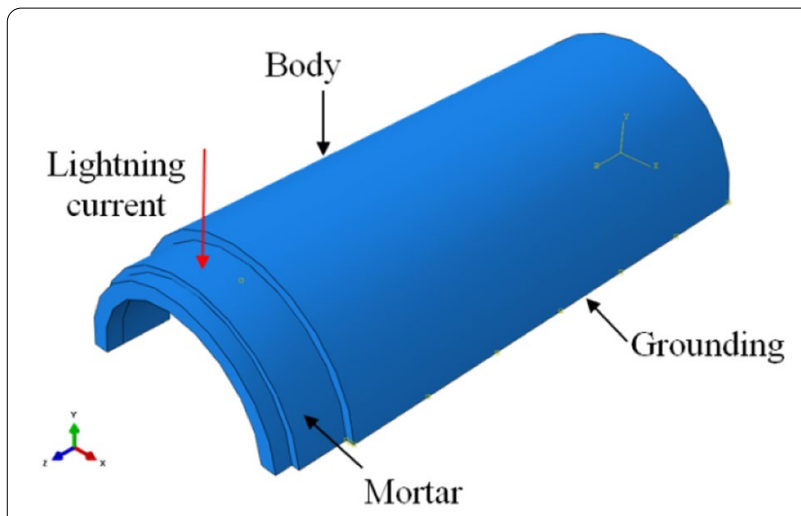

Fig. 3 Electrical-thermal coupling FEM of mortar-containing glazed tile

stress analysis, the mechanical boundary condition is set to be completely fixed. Thermal radiation is given for all of the external surfaces except the grounded ones, and the emissivity is assumed as 0.9 .

The whole simulations are conducted in two phases. The first is the process of lightning current loading, and the element type is selected as the coupled electrical-thermal element DC3D8E. The second phase is heat transfer process, starting from the completion of loading of the lightning current with duration of $10 \mathrm{~s}$, and the element type is heat conduction element DC3D8. The thermal stress analysis with the mechanical element C3D8R is then performed by bringing in the temperature field obtained in the coupled electrical-thermal analysis result.

Studies on the structural mechanics and electricalthermal characteristics of the body and mortar glazed tile are lacking, and it is difficult to obtain the related parameters from direct monitoring. Considering the similarity between the body of tile and the composition of ceramic materials, the mechanical and thermal parameters of the body materials were set based on the ceramic materials, where the body conductivity was determined on the basis of the measurement results reported in Sect. 3.1. The mechanical and thermal parameters of the mortar materials were set with reference to those of the lime mortar. Table 2 lists the parameters.

Since the vaporization or decomposition temperature of the glazed tile body and main components of the mortar is approximately $2000^{\circ} \mathrm{C}$, the electrical-thermal characteristics of the materials will change significantly after vaporization or decomposition, which hinders the conduction of the current and makes it difficult to continue to rise. Therefore, the maximum temperature was limited to $2000{ }^{\circ} \mathrm{C}$ by involving the latent heat parameter.

\section{Results and discussion}

\section{Experiment results and discussion}

According to the analysis of the experimental results, the lightning ablation pits (Fig. 4a) or surface ablation along the flashover path (Fig. 4b) can be found on the fullenamel specimens. Detailed pit damage resulting from Joule heat could be observed using scanning electron

Table 2 Parameters for simulated materials

\begin{tabular}{llllllll}
\hline Material type & $\begin{array}{l}\text { Density } \\
\mathbf{k g} / \mathbf{m}^{\mathbf{3}}\end{array}$ & $\begin{array}{l}\text { Elastic } \\
\text { modulus } \\
\mathbf{G P a}\end{array}$ & Poisson's ratio & $\begin{array}{l}\text { Thermal expansion } \\
\text { coefficient }\end{array}$ & $\begin{array}{l}\text { Thermal } \\
\text { conductivity W/ } \\
\mathbf{( m \cdot K )}\end{array}$ & $\begin{array}{l}\text { Specific heat } \\
\mathbf{J} / \mathbf{k g}\end{array}$ & $\begin{array}{l}\text { Conductivity } \\
\mathbf{S} / \mathbf{m}\end{array}$ \\
\hline Body & 3980 & 370 & 0.22 & $6.8 \times 10^{-6}$ & 20 & 880 & $8 \times 10^{-8}$ \\
Mortar & 1600 & 30 & 0.2 & $8 \times 10^{-6}$ & 0.81 & 970 & 0.6 \\
\hline
\end{tabular}

(a)

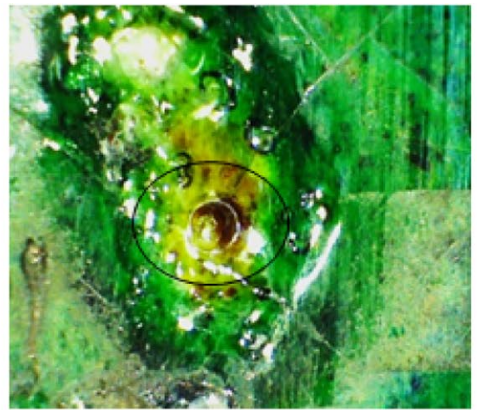

(b)

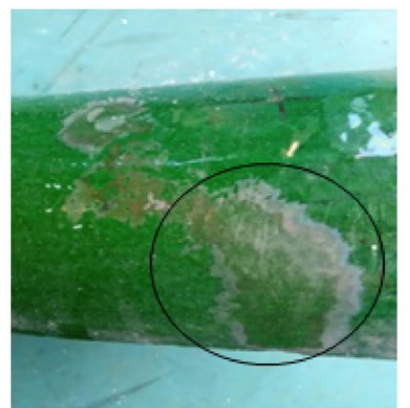

(c)

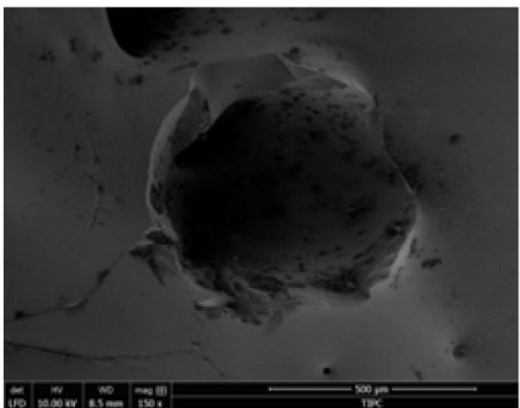

Fig. 4 Damage to enamel of glazed tile due to lightning strike, a Ablation pit in enamel; b Surface ablation in enamel; c Pit damage observed by SEM 
microscopy, as shown in Fig. 4c. The monitored results of the lightning strike at different attachment positions on the glazed tile specimens obtained using the high-speed camera could be found in the reference [21] which we have published. The results demonstrate that when the lightning current struck a location with a lower electrical conductivity, the energy was released mainly by flashover through the surface of the glazed tile, and it was difficult for the lightning current to enter the tile before the accumulation of Joule heat. This was why no significant damage effect, such as fracturing or cracking, was observed in the tile in the experiments.

Figure 5 shows the observation results of the artificial lightning current-attached mortars in the two tile specimens. The "bear head" of the glazed tiles in both the experiments nearly covered the complete mortars, with a thickness of approximately $1 \mathrm{~cm}$. It might be due to the increase in temperature produced by Joule heat effect after the lightning current was injected into the mortar. In addition, an explosion-like loud sound was heard in both the experiments, and all the glazed tiles burst completely with scattered tile debris under the test platform after the experiment, as shown in Fig. $5 \mathrm{a}$ and $\mathrm{b}$.

As shown in Figs. 4, 5, since the conductivity of the mortar area is relatively high and the conduction process of the current in the mortar is affected by Joule heat, it is inferred that the damage process due to the lightning current to the glazed tiles is as follows. The current at the surface was transmitted inside the mortar where it released because of the relatively high conductivity after the mortar of the glazed tile was struck by lightning; it also produced Joule heat during conduction and the mortar temperature increased. Subsequently, through the heat exchange, the temperatures of the body and enamel that were connected to the mortar also started to increase. The temperature changes resulting from Joule heat had at least two implications. The first was the destructive power or thermal stress resulting from the temperature changes due to Joule heat and local heterogeneous temperature distribution. The second was the rapid vaporization and expansion of the water in the internal voids of the glazed tiles, which produced a strong pressure or even local explosion (explosive force). Under the combined effect of these two forces, the strength and stability of the glazed tiles changed, and ultimately, the yield strength of the material was exceeded, causing the glazed tiles to fracture and finally undergo significant damage, as shown in Fig. 5a and b.

\section{Simulation results and analyses Validation of the numerical simulation method}

The lightning current showed in Fig. 2c was applied in the simulations of the coupled electrical-thermal effect to testify the effectiveness of the method. Figure 6 shows the simulated temperature field distributions at different times. When the lightning current was loaded at $8 \mu \mathrm{s}$ (wave head), the high-temperature field was mainly in the mortar. At the end moment of lightning current loading $(100 \mu \mathrm{s})$, the temperature field magnitude was quite high, and the temperatures in all the parts of the mortar had reached a very high value. The temperature of the adjacent body also significantly increased to more than $100{ }^{\circ} \mathrm{C}$, as shown in Fig. 6(a). After the loading of the lightning current was completed, the temperature of the glazed tiles started to reduce instead of continuing to increase. It took approximately $10 \mathrm{~s}$ for the temperature of the glazed tile to reduce to $25^{\circ} \mathrm{C}$, as shown in Fig. 6b-d.

Under the effect of lightning current, the temperature in the glazed tiles showed an uneven gradient distribution. The temperature of the mortar exhibited an evident increase because of its high electrical conductivity. However, the body had a narrow temperature spread range because of its lower conductivity, and a significant rise in the temperature was only observed in the part of the junction between the mortar and the body. (a)

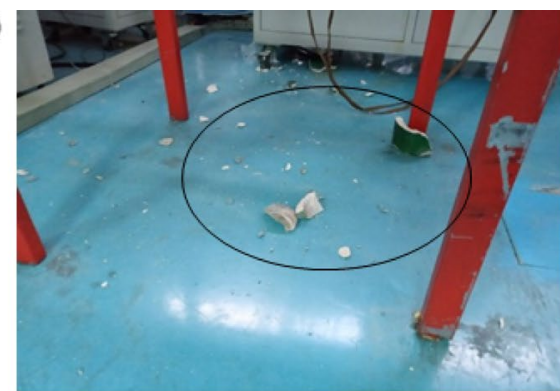

(b)

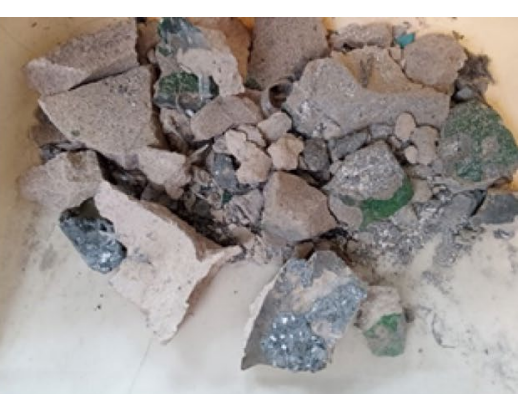

Fig. 5 Damage to glazed tiles after artificial lightning strike on mortars, a Fractures of glazed tiles after lightning strike under the platform; $\mathbf{b}$ Collected fractures of glazed tiles 


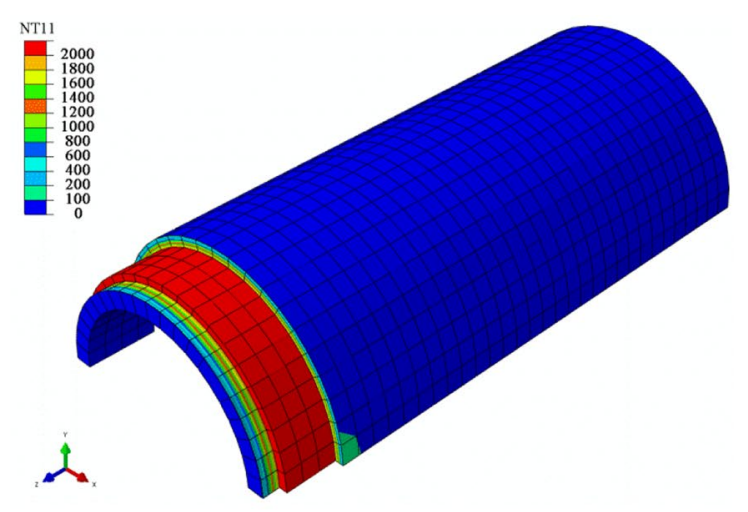

(a)

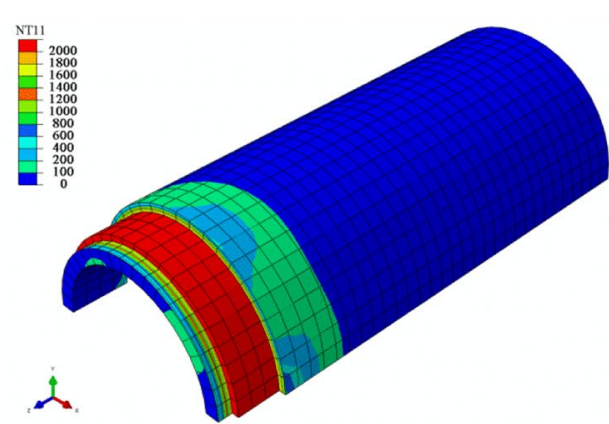

(b)

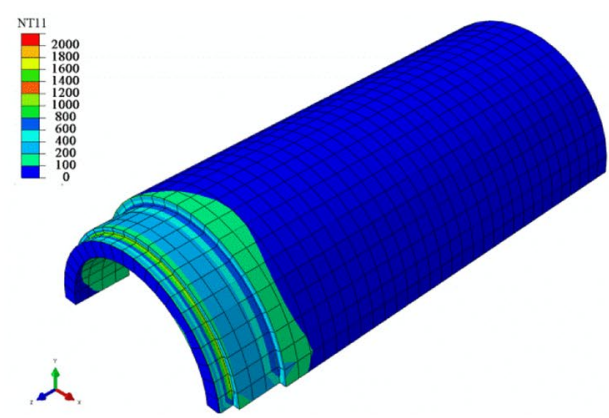

(d)

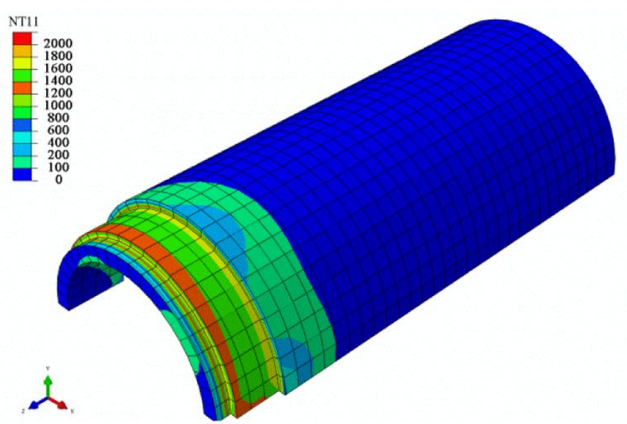

(c)

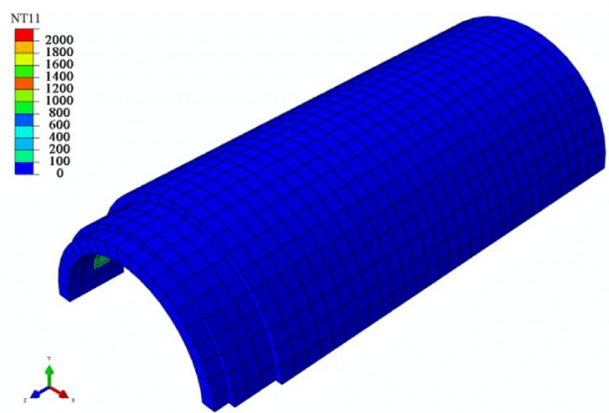

(e)

Fig. 6 Temperature distributions of mortar-containing glazed tiles at different times under $8 / 20 \mu$ s lightning current waveform with peak of $40 \mathrm{kA}$, a $8 \mu \mathrm{s} ; \mathbf{b} 100 \mu \mathrm{s} ; \mathbf{c} 0.16 \mathrm{~s} ; \mathbf{d} 1.19 \mathrm{~s} ; \mathbf{e} 9.78 \mathrm{~s}$

Figure 7 presents the thermal stress distribution of the glazed tiles at the end of the $8 / 20 \mu$ s lightning current waveform with peak of $40 \mathrm{kA}$. As observed, under Joule heat, the thermal stresses of the mortar and adjacent body zone of the tile reach the upper damage threshold limit, $0.172 \mathrm{GPa}$, whereas the thermal stress at the junction of the mortar and body as well as the grounding rail was more significant, even higher than the upper damage threshold limit of $0.9 \mathrm{GPa}$. Comparing Fig. 7 with 6 , the area with a thermal stress greater than $0.172 \mathrm{GPa}$ is mainly concentrated in areas with significant temperature differences, such as the connection between the mortar and body as well as the connection between the body and the grounding rail. Under the thermal stress induced by the regional uneven temperature distribution and explosive force inside the tiles due to vaporization, the swelling in the internal tiles accelerated and finally surpassed the yield strength, leading to deformation, cracks, and even fractures. From the results shown in Fig. 7, the spatial distribution and change range of the thermal stress are in good agreement with the experimental results; thus, the effectiveness of the simulations is validated.

As has been discussed previously, the high thermalstress mainly occurs in the area where the temperature 


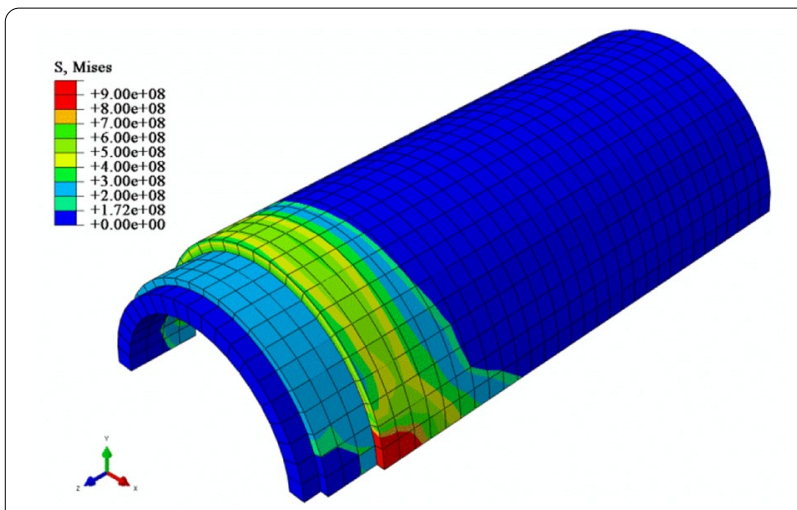

Fig. 7 Thermal stress distribution of mortar-containing glazed tile at the end of the $8 / 20 \mu$ s lightning waveform current with peak of $40 \mathrm{kA}$ (at $100 \mu \mathrm{s}$ )

changes intensely. Since the current is always transmitted to the ground, and the conductivity of the mortar part is relatively higher than that of the glaze part, the temperature change of the connection area near the ground position is the fastest, as is shown in Fig.6. Therefore, the thermal-stress in this area is the largest, as the red area appears in Fig. 7.

\section{Damage effect analysis under 10/350 $\mu$ s current waveform} Considering the parameters of the lightning current that the glazed tiles encountered is mainly $10 / 350 \mu$ s [27], theoretical $10 / 350 \mu$ s currents with different peak values are applied in the simulation to investigate the damage effect in detail. The distributions of the temperature and thermal stress of the mortar-containing glazed tiles at the end ( $2 \mathrm{~ms}$ ) of the $10 / 350 \mu$ s lightning current waveform were obtained through simulations, to study the effect of the change in the peak lightning current on the damage to the glazed tiles. Figure 8 shows the simulation results. A comparison of the temperature distribution and thermal stress under different peak currents shows that, as the peak increased, the expanding range continues to increase despite the same loading duration of the current, and the high thermal stress area also keeps increasing and expands toward the tile ridge. The areas with the thermal stress over the damage threshold of $0.172 \mathrm{GPa}$ are mainly at locations that show heterogeneous temperature distributions. Figure $8 \mathrm{~b}$ shows that, when the peak lightning current reaches $80 \mathrm{kA}$, the thermal stress in almost the entire body zone have surpassed $0.172 \mathrm{GPa}$, suggesting that the total fracturing damage is likely to occur in the glazed tiles.

As the lightning current enhanced, the areas with high temperatures and thermal stress in the initial stages sharply increased (Fig. 8 a1-b1-c1, a2-b2-c2), and the increments were significant; as the lightning current continued to enhance in the following stages, the ranges of the high temperature and thermal stress showed slow increase (Fig. 8 c1-d1-e1, c2-d2-e2). A preliminary analysis concluded that the tile had a limited capacity to conduct current in the body through the mortar, and when the lightning current was small, the magnification in the high-temperature area was evident, whereas it was not evident due to the influence of conduction channel when the lightning current was high. Unlike the results shown in Fig. 7, despite the highest temperature in the entire mortar area shown in Fig. 8, the temperature at the connection between the mortar and body grew significantly because of the long duration of the $10 / 350 \mu \mathrm{s}$ current waveform, leading to a minor temperature difference and thus a lower thermal stress in the mortar. Additionally, similar to the results shown in Fig. 7, the high-thermal-stress area appeared in the body connected to the grounding rail, extending to the ridge of the tile, as shown in Fig. 8. This can be attributed to the ease of lightning current conduction toward the grounding rail, which caused frequent changes and an uneven distribution of the temperature in the grounding rail.

In general, the combination of the experiments and the numerical analysis results demonstrate that the damage mechanism of lightning strike to glazed tiles may include two aspects. The first is the internal explosive force generated from the sharp vaporization and expansion of the moisture inside the tiles due to rapid temperature increase, and the second is the thermal stress caused by the uneven temperature distribution.

\section{Conclusions}

Artificial lightning strike tests and coupled electricalthermal analyses were carried out in this paper to investigate the causes and damage effect of roofing glazed tiles due to lighting current. In the reinforcement and sealing technology of glazed tiles, the prevention of lightning damage should be considered. The following conclusions can be drawn:

(1) Joule heat effect is the main damage cause of lightning strike, as the tile damaged significantly when lightning current attached to the mortar with high electrical conductivity, while only surface flashover was observed when attached to the surface of the enamel and body with low electrical conductivity.

(2) Evident gradient distribution of temperature can be found in the coupled thermal-electrical simulation, and the range extended as the peak of the lightning current increased. The location with high temperature value concentrated in the mortar while the high thermal-stress area mainly appeared in the 


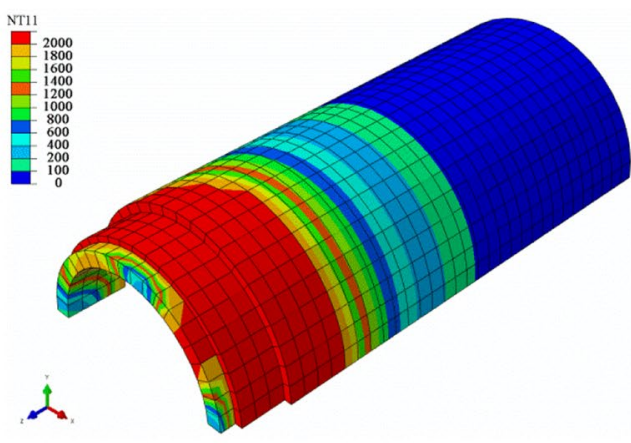

(a1)

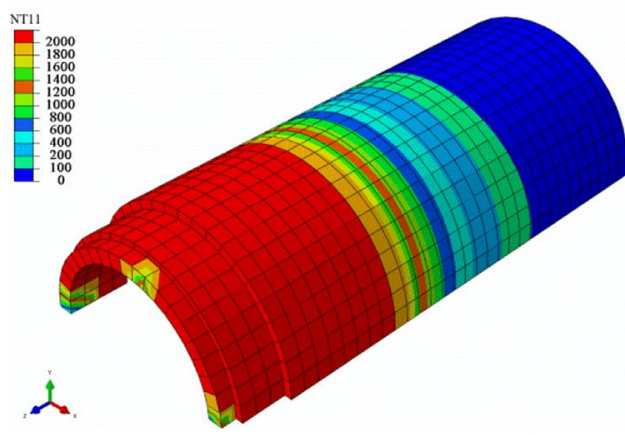

(b1)

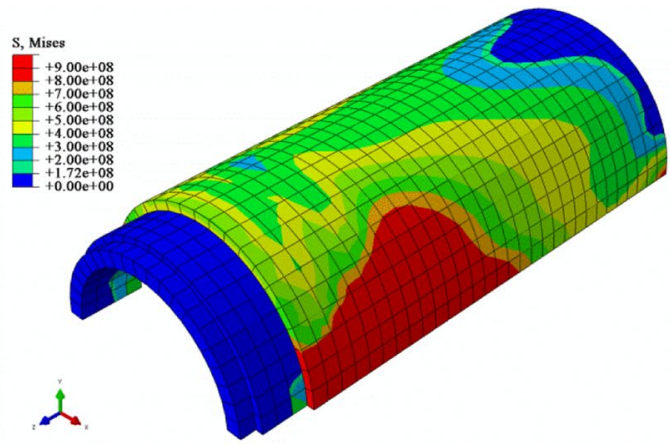

(a2)

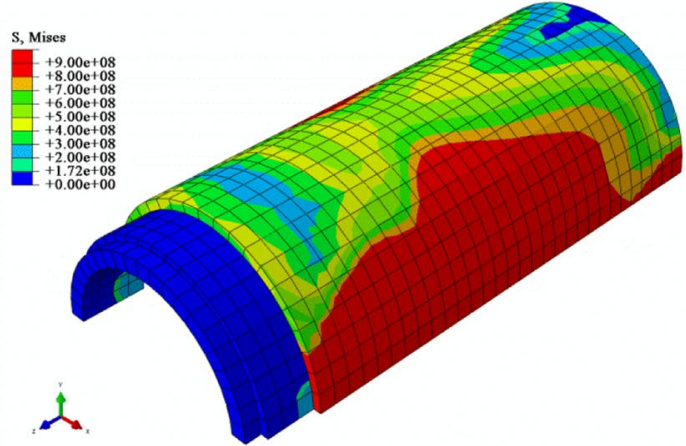

(b2)

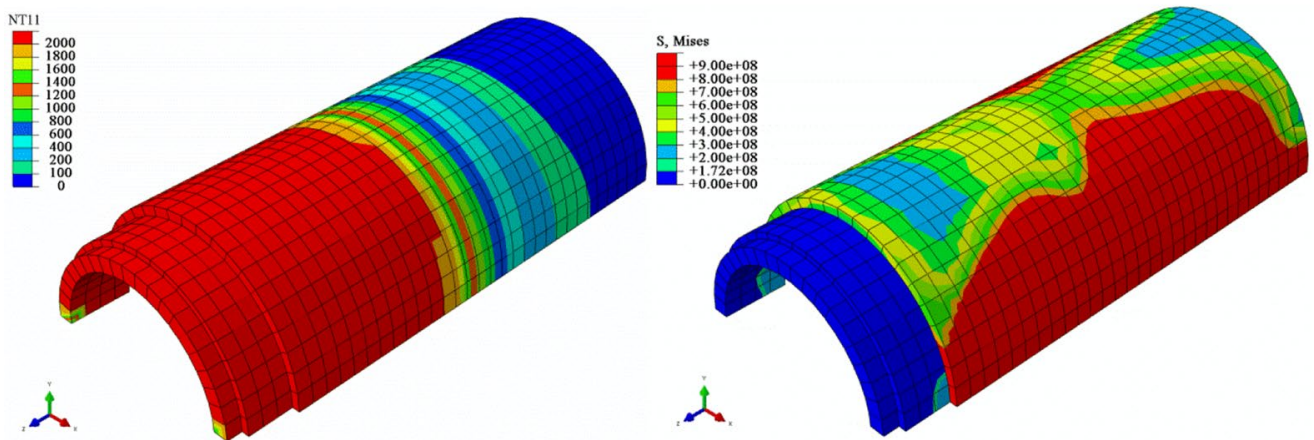

Fig. 8 Temperature and thermal stress fields of mortar-containing glazed tiles on completion of 10/350 $\mu$ s current waveform with different peaks (at 2 ms), a 1 Temperature at $40 \mathrm{kA}$; a2 Thermal stress at $40 \mathrm{kA}$; b1 Temperature at $80 \mathrm{kA}$; b2 Thermal stress at $80 \mathrm{kA} ; \mathbf{c} 1$ Temperature at $120 \mathrm{kA} ; \mathbf{c} 2$ Thermal stress at 120 kA; d1 Temperature at 160 kA; d2 Thermal stress at 160 kA; $\mathbf{1} 1$ Temperature at 200 kA; e2 Thermal stress at 200 kA

position where the temperature distribution was not uniform.

(3) The damage mechanism of lightning Joule heat effect to glazed tiles may rely on two aspects. One is the internal explosion force generated from the sharp vaporization and expansion of the moisture inside the tiles due to the increase of rapid temperature, and the other is the thermal stress caused by the uneven temperature distribution. 
(c1)

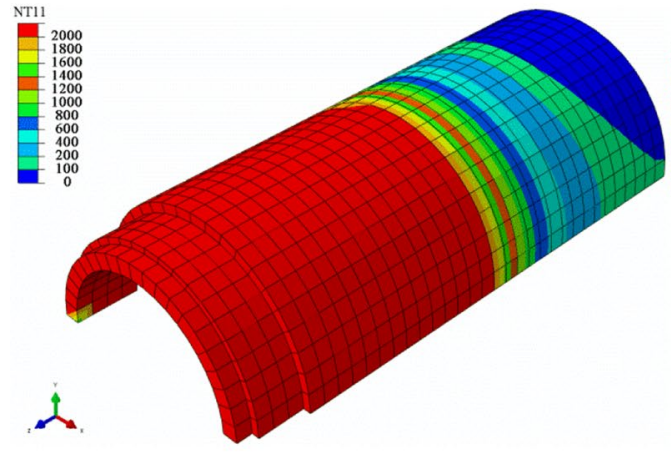

(d1)

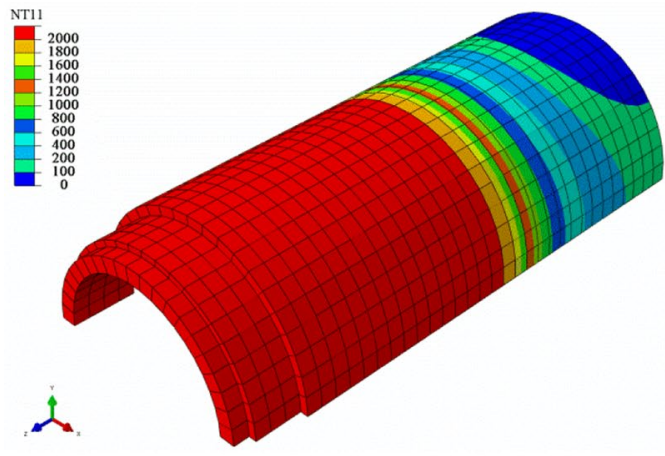

(e1) (c2)

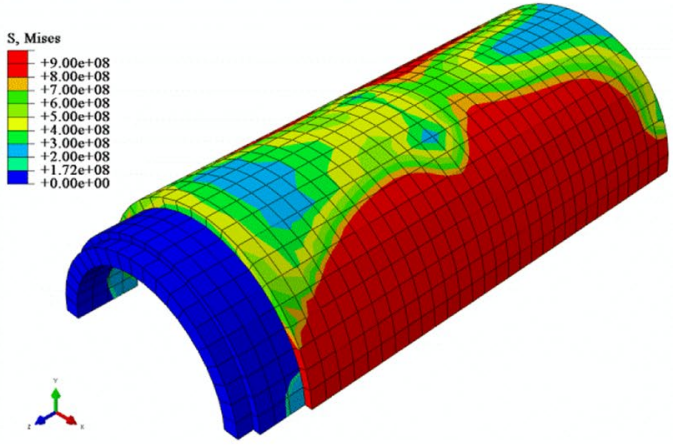

(d2)

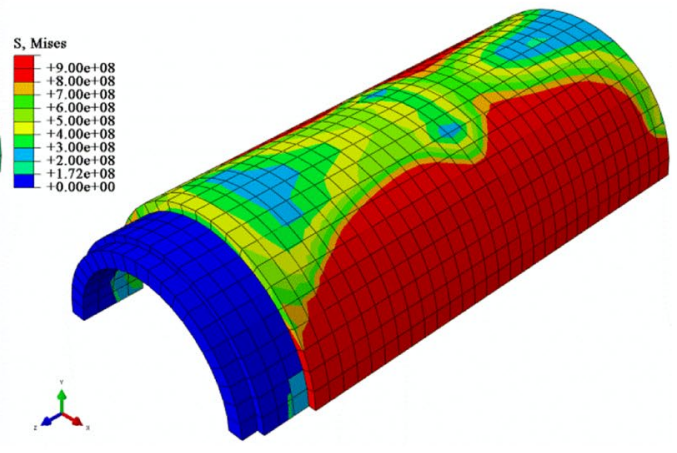

(e2)

Fig. 8 continued

\section{Acknowledgements}

The experiments were carried out in national key laboratory on electromagnetic environmental effects and electro-optical engineering, army engineering university of PLA, and the authors would like to express their gratitude to this laboratory. The authors are also thankful to the anonymous reviewers for their valuable comments.

\section{Authors' contributions}

$J L$ and SF wrote the manuscript. JL, SF and LS designed and performed the experiments. $J \mathrm{~L}, \mathrm{ZF}$ and $\mathrm{LF}$ analyzed the experimental result. SF, ZF and $\mathrm{YL}$ conducted FEM analysis and interpreted the results. YL and $\mathrm{PH}$ provided the samples. All authors read and approved the final manuscript.

\section{Funding}

This study is financially supported by the Beijing Natural Science Foundation (Grant No. 8192052).

\section{Availability of data and materials}

All data generated during this study are included in this published article.

\section{Declarations}

\section{Competing interests}

The authors declare no conflict of interests.

\section{Author details}

'Beijing Meteorological Disaster Prevention Center, Beijing 100089, China. ${ }^{2}$ National Key Laboratory on Electromagnetic Environmental Effects and Electro-Optical Engineering, Army Engineering University of PLA, Nanjing 210007, China.
Received: 4 May 2021 Accepted: 24 August 2021

Published online: 13 September 2021

\section{References}

1. Zhao J, Li WD, Luo HJ, Miao JM. Research on protection of the architectural glazed tiles in the Palace Museum. J Cult Herit. 2010;11(3):279-87.

2. Svorová PS, Rohanová D, Svora P. Gothic green glazed tile from Malbork Castle: multi-analytical study. Herit Sci. 2017;5:27. https://doi.org/10.1186/ s40494-017-0141-6.

3. Elisa A. The steeple spire of the Parma Cathedral: an analysis of the glazed bricks and mortars. J Eur Ceram Soc. 2013;33(13-14):2801-9.

4. An Z, Liu B. Chinese historic buildings fire safety and countermeasure. Procedia Engineering. 2013;52:23-6.

5. Hu J and Li C. Lightning protection of Chinese ancient architecture. In: 7th Asia-Pacific international conference on lightning. 2011. p. 844-847. Doi: https://doi.org/10.1109/APL.2011.6110245.

6. Richter J. The Ancient lightning rods around the Mediterranean Sea. Academia. edu. 2015.

7. Philip KE. Benjamin Franklin and lightning rods. Phys Today. 2006;59:42-8. https://doi.org/10.1063/1.2180176.

8. Mikeš J, Efmertová M. Development of lightning rod for lightning protection standard in Europe, especially in Czech lands. J Electrostat. 2013;71:597-601. https://doi.org/10.1016/j.elstat.2012.12.016.

9. Huang $\mathrm{Y}, \mathrm{Ma} \mathrm{H}$, Guo J. Lightning experiments of building materials for the Forbidden City and suggestions for improving lightning protection design of Chinese ancient buildings. In: Proceedings of Institute of electrical engineering, Chinese Academy of Sciences, vol 18. 1989. p.110-117.

10. Chen H, Huang X, Zhu Z, Tang H. Study on refined protection of lightning risk assessment for Potala Palace area. In: 33rd Annual meeting of China Meteorological Society, Xi'An, China. 2016. p.84-90. 
11. Li JX, Zhang XQ, Li J, Li RJ, Qian MH, Song PJ. An experimental study of the damage degrees to ancient building timber caused by lightning strikes. J Electrostat. 2017;90:23-30.

12. Mikeš J, Efmertová M, Kutac J, Martinek Z. Influence of the wall material of the lightning protected object size induced surges. In: 32nd International conference on lightning protection (ICLP), Shanghai, China. 2014. p.1716-1719. Doi: 10.1109 /ICLP.2014.6973432.

13. Zischank W, Heidler F, Wiesinger J, Metwally I, Kern A, Seevers M. Laboratory simulation of direct lightning strokes to a modeled building: measurement of magnetic fields and induced voltages. J Electrostat. 2004;60(2-4):223-32.

14. Masaji S, Kuramoto $S$. Experimental direct lightning current distribution in a reinforced concrete building. Electron Commun Jpn. 2000:83(4):53-62.

15. Chen JQ, Zhou BH, He HB. The damage effects due to lightning. Saf EMC. 2004;6:44-8.

16. Hirano $Y$, Katsumata $S$, Iwahori $Y$, Todoroki A. Artificial lightning testing on graphite/epoxy composite laminate. Compos A Appl Sci Manuf. 2010:41(10):1461-70.

17. Kawakami H, Feraboli P. Lightning strike damage resistance and tolerance of scarf-repaired mesh-protected carbon fiber composites. Compos Part A. 2011;42(9):1247-62

18. Chemartin L, Lalande P, Peyrou B, Chazottes A, Elias PQ, Delalondre C, Cheron BG, Lago F. Direct effects of lightning on aircraft structure: analysis of the thermal, electrical and mechanical constraints[J]. Aerospace Lab. 2012;1(15):1-15.

19. Naghipour P, Pineda EJ, Arnold SM. Simulation of lightning-induced delamination in un-protected CFRP laminates. Appl Compos Mater. 2016;23(4):523-35.
20. Liu XB. Investigation of the chemical characteristics and bonding mechanism of Chinese traditional lime mortars, Zhejiang University. 2015. p.37-38.

21. Li JX, Fu SC, Zhang T, Li J, Huo PD, Li Y. Investigation of lightning damage mechanism and flashover channels on glazed roofing tiles of ancient buildings through laboratory experiments. J Electrostat. 2021. https://doi. org/10.1016/j.elstat.2021.103553.

22. Ogasawara T, Hirano Y, Yoshimura A. Coupled thermal-electrical analysis for carbon fiber/epoxy composites exposed to simulated lightning current. Compos A. 2010;41(8):973-81.

23. Li Y, Miao J, Zhang R. Research on the types of pores in Ancient architectural glazed tile of Ming and Qing dynasty in China. J Guangxi Univ Technol. 2013;24(02):68-73.

24. Hui R, Wang L, Liang J, Wei C, Li H. Investigation of the superficial pulverization of glazed tile components of Chinese ancient building. Sci Conserv Archaeol. 2007;19(2):14-9, 73.

25. Kornmann M, CTTB. Clay bricks and roof tiles, Manufacturing and properties. Soc. Industrie Minérale edit. Paris; 2007. ISBN 2-9517765-6-X

26. Zhu Z, Ye L, Wang M. An investigation of glaze-fit problems for fine earthenware. J Chin Ceram Soc 1978; 04: 266-278, 329, 336

27. Protection against lightning — part 1: General principles: IEC 62305-1. 2010

\section{Publisher's Note}

Springer Nature remains neutral with regard to jurisdictional claims in published maps and institutional affiliations.

\section{Submit your manuscript to a SpringerOpen ${ }^{\circ}$ journal and benefit from:}

- Convenient online submission

- Rigorous peer review

- Open access: articles freely available online

- High visibility within the field

- Retaining the copyright to your article

Submit your next manuscript at springeropen.com 